\title{
DE LÍNGUA ESTRANGEIRA À LÍNGUA FRANCA E OS PARADOXOS IN-BETWEEN: (TENSIONANDO) O ENSINO DE LÍNGUA INGLESA À LUZ DA BNCC
}

\author{
From foreign language to lingua franca and the paradoxes in-between: \\ (tensioning) ELT in the light of the BNCC
}

\author{
Juliana Silva SANTANA \\ Secretaria de Educação do Estado da Bahia \\ julissemail@gmail.com \\ http://orcid.org/0000-0002-7736-8706
}

Felipe Flores KUPSKE Universidade Federal da Bahia kupske@gmail.com http://orcid.org/0000-0002-0606-612X

RESUMO: Este artigo tem como objetivo principal investigar algumas mudanças na redação para o ensino da língua inglesa entre a segunda (2016) e a terceira versão (2018) da Base Nacional Comum Curricular (BNCC). Sem negar a importância da língua inglesa no currículo brasileiro e sempre considerando os avanços que a BNCC traz à tona em nosso contexto educacional, este trabalho apresenta uma leitura crítica da BNCC, tensionando não apenas a exclusão de outras línguas estrangeiras, como, também, alguns de seus índices mercadológicos e paradigmas em torno da fundamentação teórica e do currículo propostos para o inglês como língua franca (ILF).

PALAVRAS-CHAVE: Ensino de Língua Inglesa; BNCC; Inglês como Língua Franca.

\begin{abstract}
The main objective of this article is to investigate the changes in relation to ELT in the second (2016) and third (2018) versions of the Brazilian National Common Curricular Base (BNCC). Without denying the importance of the English language in the Brazilian curriculum and always considering that there are positive theoretical and practical features in the document, this work presents a critical reading of the Base, tensioning not only the exclusion of other additional languages, but also some of its market indexes and paradigms on the theoretical foundation and curriculum proposed for English as a lingua franca (ELF)
\end{abstract}

KEYWORDS: English Language Teaching; BNCC; English as a Lingua Franca. 


\section{INTRODUÇÃO}

A terceira e última versão da Base Nacional Comum Curricular (BNCC), homologada em dezembro de 2018, atualmente em fase de implementação, é o documento orientador obrigatório do Ensino Básico brasileiro que tem como objetivo assegurar uma formação básica comum, como já pretendido por meio da Lei de Diretrizes e Bases (LDB - BRASIL, 1996). A BNCC, então, vem à tona para definir os padrões curriculares de todas as escolas públicas e privadas de Educação Infantil, Ensino Fundamental e Ensino Médio no Brasil.

Muito embora, como sinalizado por Plank (2016), a adoção de padrões engessados possa ser uma estratégia robusta na melhoria das oportunidades educacionais no Brasil, o endosso da Base $^{1}$ ainda é política e academicamente controverso e, em termos práticos, até então, não está claro de que maneira os novos padrões curriculares guiarão os ganhos educacionais nacionais. Enquanto para alguns profissionais da área de linguagens, como Plank (2016), a adoção de um núcleo comum marca um grande avanço para o Brasil, outros são manifestamente contra a implementação da última versão da Base. Tílio (2019), por exemplo, desafia um "currículo único, impositivo, verticalizado e autoritário, estabelecendo de forma prescritiva e obrigatória, conteúdos comuns (...) para todas as Disciplinas, para todo o território nacional" (TílIO, 2019, p. 12). Na mesma direção, Considera (2019) relata, em oposição a um currículo comum único, que um currículo flexível sempre se apresentou como um ponto de ordem no campo teórico da Educação, entendido como um "processo mais justo, equânime, articulado, orgânico e contínuo (...)" (CONSIDERA, 2019, p. 68).

Em adição, além do debate acerca da constituição de um bloco único de conhecimentos para todos os estudantes do país, conforme argumenta Tílio (2019), devemos lembrar do contexto em que a Base foi construída e aprovada. Para o autor, a BNCC foi iniciada em um governo democraticamente eleito, mas "foi terminada em um governo em que o vice-presidente assumiu o posto de titular, após um processo de impeachment nitidamente marcado por articulações políticas" (TÍLIO, 2019, p. 9). Em consonância com o cenário político de 2018, para Szundy (2019), uma versão mais

\footnotetext{
${ }^{1} \mathrm{O}$ termo Base será usado como sinônimo para fazer menção à Base Nacional Comum Curricular (BNCC).
} 
tecnicista da Base, em comparação a versão anterior (ancorada na consulta pública), acaba sendo aprovada. Muito embora o percurso de desenvolvimento inicial da Base tenha contato com a participação da sociedade e de unidades escolares e órgãos relacionados à educação, através, por exemplo, de consultas públicas via internet ${ }^{2}$ e seminários, há, ainda, o questionamento sobre o quanto a participação popular foi efetivamente considerada na elaboração do documento final. Aparentemente, a última versão da BNCC (BRASIL, 2018) suprimiu a participação popular ocorrida ao longo do processo. Em outras palavras, a construção colaborativa foi interrompida, e a última versão foi publicada de modo autoritário.

Percebemos, assim, que a implementação da BNCC é ainda bastante efervescente. Inseridos no Dossiê Temático Políticas linguísticas oficiais e oficiosas: da BNCC ao Escola sem Partido, organizado pelas professoras Alessandra Coutinho Fernandes (UFPR), Ana Paula Beato-Canato (UFPR) e Juliana Zeggio Martinez (UFPR), compreendemos que o momento atual demanda reflexão e tensionamento em relação aos discursos e práticas relacionados ao ensino de línguas. Sem negarmos a importância da língua inglesa no currículo brasileiro e sempre considerando os avanços teóricos da Base, apresentaremos uma leitura crítica de alguns de seus trechos. Tomamos leitura crítica, neste texto, como uma leitura analítica, reflexiva e ativa que nos permite descobrir ideias subjacentes dentro do texto da BNCC.

Em seu movimento de elaboração, a Base sofreu mudanças de redação, sobretudo entre a segunda e terceira versões, que acabaram redesenhando, por exemplo, seus princípios orientadores. Entre as alterações mais perceptíveis para o componente língua inglesa entre a segunda e terceira versões, foco deste estudo, estão: (i) a substituição de uma seção de Língua Estrangeira, mais generalista, por uma seção específica de língua inglesa, tomada como única língua não nativa obrigatória para o ensino básico; e (ii) a mudança do status da língua inglesa de língua estrangeira (LE) para língua franca (LF).O presente trabalho, então, tem como objetivo principal destacar e problematizar essas alterações na redação entre as duas últimas versões da BNCC (BRASIL 2016; 2018) relacionadas à área do ensino de língua inglesa no Brasil que trazem à tona, ao nosso ver,

\footnotetext{
${ }^{2}$ Conforme o Ministério da Educação (MEC). Disponível em: <http://basenacionalcomum.mec.gov.br/historico > . Acesso em: 14 ago. 2020.
} 
descompassos teóricos e práticos. Buscamos evidenciar e tensionar o gesto de exclusão de outras línguas não nativas (e.g. espanhol) na última versão do documento, bem como alguns de seus índices mercadológicos e paradigmas criados em torno da fundamentação teórica e do currículo proposto para o inglês como língua franca (ILF). Refletimos, sempre que possível, acerca das implicações pedagógicas que essas mudanças de redação revelam. Uma vez que a língua inglesa está presente na BNCC no texto do Ensino Fundamental Anos Finais - e do Ensino Médio, essas serão as etapas de ensino abordadas neste trabalho.

Este artigo está dividido em cinco seções. Na primeira, discutimos a criação da BNCC. Atenção especial à língua inglesa, foco desta empreitada, é dada em nossa segunda seção. Na terceira, discutimos a mudança, na redação do documento, da seção de inglês como língua estrangeira (ILE) para inglês como língua franca (ILF). Os paradoxos, em nossa opinião, criados entre teorias do ILF e o currículo proposto pela Base serão discutidos na quarta e na quinta seção. Por fim, além dessas seções, apresentamos nossas considerações (nada) finais.

\section{A CONSTRUÇÃO DA BNCC: INFLUÊNCIAS E DOCUMENTOS NORTEADORES}

O discurso de unificação curricular para o ensino no Brasil é um tema presente em impressos oficiais anteriores à BNCC (e.g. LDB e PCNs). Ao longo dos anos, podemos perceber uma organização documental baseada em torno da narrativa de se diminuir as diferenças entre os currículos deste país continental e plural para que não haja defasagem na formação cidadã e profissional entre as suas várias regiões e estados. A criação de uma base comum para todo território brasileiro, por exemplo, foi descrita na LDB nº 9.394/96, no Art. $9^{\circ}$, inciso IV:

(...) estabelecer, em colaboração com os estados, o Distrito Federal e os municípios, competências e diretrizes para a educação infantil, o ensino fundamental e o ensino médio, que nortearão os currículos e seus currículos mínimos, de modo a assegurar formação básica comum. (BRASIL, 2016, p. 9).

Ainda nesse mesmo artigo, há a determinação da criação do Plano Nacional de Educação 
(PNE) e de um Conselho Nacional de Educação (CNE) para promover a execução e a fiscalização das propostas.

Todo esse aparato legal configura o despertar das atividades em direção ao desenvolvimento de um currículo comum. Até a criação da BNCC, foram desenhados os Parâmetros Curriculares Nacionais (BRASIL, 1997; BRASIL, 1998; BRASIL, 2000), as Orientações Curriculares Nacionais (OCN) (BRASIL, 2006) e as Diretrizes Curriculares Nacionais (DCN) (BRASIL, 2010) que direcionaram o ensino no Brasil por muitos anos, mas que possuíam um cunho orientador e não prescritivo. Podemos perceber, nos documentos citados, um discurso orientado para uma base comum, que diz ter preocupação com a formação do indivíduo, mas também com uma formação para o mercado de trabalho, revelando, assim, para Lopes e Caprio (2018), os primeiros sintomas de um caráter neoliberalista para a educação nacional. Na mesma linha, Szundy (2019) aponta que currículos comuns, padronizados, são geralmente desenvolvidos levando-se em consideração uma formação voltada ao mercado de trabalho. Em consonância, Malerba (2017) sinaliza que bases curriculares comuns são guiadas por diretrizes pragmáticas, utilitárias, de fundo liberal, dando ênfase na construção e prioridades do indivíduo e não da coletividade.

Embora a criação de uma base curricular comum para o ensino brasileiro estivesse prevista desde a LDB de 1996, o percurso de criação da BNCC foi iniciado apenas em 2015 com a publicação do texto de sua primeira versão. Essa versão preliminar foi posta em consulta pública ${ }^{3}$ por meio do site do Ministério da Educação $(\mathrm{MEC})^{4}$, incluindo a comunidade em geral, com maior foco nos estudantes, pais e professores. Considerando as informações coletadas através dessa consulta e a análise feita por especialistas, a segunda versão foi publicada em 2016, discutida e analisada em 27 seminários estaduais. No comando do governo pós-impeachment ${ }^{5}$ de 2016, a terceira versão da Base foi publicada no início de 2017, passando por cinco audiências públicas e por análise de especialistas. As alterações foram embargadas pelo CNE e, sem mais consultas, foi homologada em dezembro do mesmo ano. Esse trecho da terceira versão da BNCC, homologado em 2017,

3 Conforme MEC. Disponível em: <http://pne.mec.gov.br/notícias/473-consulta-publica-sobre-basenacional-comum-recebeu-mais-de-12-milhoes-de-contribuições $>$. Acesso em: 14 ago. 2020.

${ }_{5}^{4}$ Disponível em: <https://www.gov.br/mec/pt-br>. Acesso em: 14 ago. 2020.

${ }^{5}$ Governo pós-impeachment refere-se ao governo de Michel Temer, vice-presidente que assumiu a presidência devido à destituição da presidenta Dilma Rousseff, em agosto de 2016. 
discorria apenas sobre os Ensinos Infantil e Fundamental. Em 2018, a versão completa, contemplando o Ensino Médio, foi aprovada. Essa versão passou por cinco novas audiências públicas e foi embargada pelo CNE.

No mesmo período, a Reforma do Ensino Médio estava em elaboração. A redação da BNCC do Ensino Médio, assim, já demonstrava um forte alinhamento com o documento da Reforma, alvo de muitas tensões e conflitos. De acordo com Aguiar e Tuttman (2020), os conflitos giravam em torno de duas perspectivas:

uma que situa a educação de qualidade para todos no contexto de um país com extrema desigualdade social e que defende mudanças sociais e econômicas profundas em prol de uma sociedade mais justa; e outra que prioriza a formação para o trabalho na lógica do mercado, favorecendo o gerencialismo, o estabelecimento de competências e a cultura da performatividade. (AGUIAR; TUTTMAN, 2020, p. 72).

Assim, o MEC, frente às grandes pressões relacionadas aos opositores da Reforma, declarou que realizaria alterações no texto da BNCC para o ensino médio. Com a promessa de fazer essas alterações, conseguiu, então, atenuar as tensões, mas "visou apenas garantir a aprovação da Base ainda em 2018, sem mudanças estruturais no texto. [...] e sem qualquer aviso prévio, o CNE aprovou a BNCC do ensino Médio" (CÁSSIO, 2019, p. 31). Dessa forma, o MEC abrandou as tensões em relação à Reforma dessa etapa de ensino, não efetivou as alterações alvo de polêmicas e, sem mais consultas ou discussões, realizou a homologação da BNCC no último mês de mandato do governo em vigência, em dezembro de 2018, revelando pressa em sua aprovação (CONSIDERA, 2019). Para Considera (2019),

(...) apesar de toda a mobilização de diversos setores da educação em torno da crítica à maneira açodada que tanto a Reforma do Ensino Médio quanto a BNCC foram pensadas e levadas a cabo, o MEC seguiu normalmente seu planejamento aligeirado e antidemocrático das rodadas de debates sobre assuntos que mereciam mais atenção dos órgãos formuladores de políticas públicas para a educação pública. (CONSIDERA, 2019, p. 55).

Assim, a arquitetura geral da Base acaba atravessando vários governos e formas/níveis de participação popular em um contexto conflituoso principalmente na fase 
de sua homologação. Em outras palavras, a Base "se constituiu em campo de intensas disputas ideológicas na sua construção e aprovação, mas uma visão hegemônica burguesa acabou por aprisionar o debate com a atenção voltada para um tecnicismo excludente" (CURY; REIS; ZANARDI, 2018, p. 84). Nesse contexto, percebe-se que desde o início da elaboração da redação da BNCC houve uma grande mobilização dos setores sociais. Contudo, outras organizações não governamentais, financiadas pelo setor privado, como o Todos pela Educação ${ }^{6}$ e o Movimento pela Base $^{7}$, aparentemente, acabaram tendo uma participação mais expressiva no desenvolvimento do documento.Assim, a proposta de transparência e participação popular, ao longo do tempo, foi perdendo espaço.

Após toda essa trajetória de discussões, participações públicas e embargos, foram homologadas todas as etapas do Ensino Básico. A Base, então, apresenta-se como uma proposta curricular para todos os estados e municípios, propondo o que considera como “competências mínimas" a serem desenvolvidas em cada etapa de ensino. Essas competências devem ser desenvolvidas, de forma linear, durante cada etapa de forma obrigatória, como pré-requisitos para a próxima fase. Nesse sentido, a Base tem servido de alicerce para a elaboração dos currículos estaduais e municipais em todo o país, que seguem em concomitante implementação, seguindo a lógica de que as competências orientam a construção dos currículos. A discussão acerca das "competências mínimas" terá mais espaço nas seções que seguem.

\section{O COMPONENTE LÍNGUA INGLESA NA BNCC}

A língua inglesa integrava a grade curricular comum dos componentes a serem lecionados no Ensino Fundamental, a partir do $6^{\circ}$ ano, orientada pelo PCN do Ensino Fundamental II de 1998, e no Ensino Médio, a partir da homologação do PCN do Ensino Médio em 2000. Nesses documentos, a língua inglesa integra a seção de línguas estrangeiras, mas não há a exclusão da possibilidade de outras línguas integrarem o currículo. De acordo com a orientação do PCN (BRASIL, 2000) para o Ensino Médio, havia a opção de uma segunda língua estrangeira, de acordo com a necessidade ou anseio

\footnotetext{
${ }^{6}$ Conforme o "Todos pela Educação". Disponível em: <https://todospelaeducacao.org.br/>. Acesso em: 26 abr. 2020 .

7 Conforme o "Movimento pela Base". Disponível em: <http://movimentopelabase.org.br/quem-somos/>. Acesso em: 28 abr. 2020.
} 
da comunidade escolar. Assim, o componente língua inglesa constituía a grade básica para a formação educacional, como a língua portuguesa e a matemática, por exemplo, mas outras línguas estrangeiras poderiam ser ofertadas. A Base, por outro lado, descortina uma realidade diferente. No texto para o Ensino Fundamental, explica o documento, "a área de Linguagens é composta pelos seguintes componentes curriculares: Língua Portuguesa, Arte, Educação Física e, no Ensino Fundamental - Anos Finais, Língua Inglesa" (BRASIL, 2018, p. 61). Nesse ciclo, a língua inglesa é apresentada como um componente curricular obrigatório, tendo uma seção específica para descrevê-lo. Por uma necessidade de ampliar e diversificar as aprendizagens, o documento dispõe as diferentes linguagens em componentes curriculares. Conforme o texto da BNCC:

Por sua vez, no Ensino Fundamental - Anos Finais, as aprendizagens, nos componentes curriculares dessa área ampliam as práticas de linguagem conquistadas no Ensino Fundamental - Anos Iniciais, incluindo a aprendizagem de Língua Inglesa. (BRASIL, 2018, p. 63).

Como componente, a Base considera a função social e política do inglês - como língua franca, os multiletramentos - práticas sociais do mundo digital e "a atitude de acolhimento e legitimação de diferentes formas de expressão na língua” (BRASIL, 2018, p. 242). Assim, o componente é estruturado inicialmente pelos eixos organizadores, a saber: Oralidade, Leitura, Escrita, Conhecimentos Linguísticos e Dimensão Intercultural. Em seguida, as seis competências específicas de língua inglesa ${ }^{8}$ são definidas, organizadas em unidades temáticas, objetos de conhecimento e habilidades, detalhando-se essa estrutura para cada série da etapa.

No Ensino Médio, mantém-se a mesma distribuição dos componentes, embora não tenham a mesma obrigatoriedade, como percebemos no fragmento abaixo.

(...) a área tem a responsabilidade de propiciar oportunidades para a consolidação e a ampliação das habilidades de uso e de reflexão sobre as linguagens - artísticas, corporais e verbais (oral ou visual-motora, como Libras, e escrita) - que são objeto de seus diferentes componentes (Arte, Educação Física, Língua Inglesa e Língua Portuguesa). (BRASIL, 2018, p. 482, grifos do original).

\footnotetext{
${ }^{8}$ Conforme a BNCC (BRASIL, 2018, p. 246).
} 
Entre os componentes citados, a língua portuguesa é a única descrita de forma detalhada nesse ciclo, não existindo uma seção para tratar dos outros componentes na área de Linguagens e suas Tecnologias. Em conformidade com o trecho da BNCC a seguir, a língua inglesa é obrigatória apenas para o primeiro ano, pois, a partir do segundo ano desse ciclo, os componentes devem ser oferecidos de acordo com o itinerário formativo da área escolhida pelo estudante. No segundo e terceiro anos, o inglês será cursado caso seja considerado relevante para a área em questão. Assim, o componente deixa de ser obrigatório para todas as séries, sendo retirado do núcleo comum, em conformidade com o plano para a reforma do Ensino Médio:

Essa nova estrutura do Ensino Médio, além de ratificar a organização por áreas do conhecimento - sem desconsiderar, mas também sem fazer referência direta a todos os componentes que compunham o currículo dessa etapa - prevê a oferta de variados itinerários formativos, seja para o aprofundamento acadêmico em uma ou mais áreas do conhecimento, seja para a formação técnica e profissional. (BRASIL, 2018, p. 468).

Dessa forma, o inglês não se configura mais como um componente curricular que merece detalhamento ou presença em todo o ciclo.

A Reforma do Ensino Médio também traz uma vinculação com o ensino para a formação cidadã e profissionalizante, deixando o primeiro ano para uma formação geral, o segundo e o terceiro anos para as escolhas do estudante de acordo com as áreas de conhecimento, que podem, por exemplo, incluir o inglês na modalidade instrumental. Essa decisão é tomada a partir da terceira versão da Base (2018), na qual a seção Línguas Estrangeiras é eliminada; a língua inglesa toma, então, o espaço discursivo e curricular, figurando como única língua não nativa obrigatória na Educação Básica brasileira. Fechase, assim, o espaço para o ensino de outras línguas, como as línguas indígenas e/ou fronteiriças pertinentes para diversos estados e contextos, assim como barra-se o avanço do ensino de espanhol pelo país, que estava em pleno desenvolvimento. O ensino de espanhol estava amparado pela Lei $n^{\circ} 11.161 / 2005$, mas a Lei $n^{\circ} 13.415 / 2017$, que alterou a LDB, "revoga a Lei do Espanhol, como é informalmente conhecida a Lei $\mathrm{n}^{\circ}$ 11.161/2005, que previa a oferta obrigatória de Espanhol no Ensino Médio e facultativa no Fundamental" (VILAÇO; GRANDE, 2019, p. 149). Sendo a BNCC um documento que regula a elaboração dos currículos em toda a Educação Básica, as escolas devem adaptar 
suas práticas em função do que esse documento determina, ou seja, todas as unidades escolares brasileiras devem incluir a língua inglesa em seus currículos, gesto, para muitos, condizente como uma política linguística repressora (SZUNDY, 2019). A exclusão de outras possibilidades linguísticas será abordada mais adiante neste texto.

O direcionamento do ensino para as demandas mercadológicas é perceptível desde os PCNs, que são considerados documentos preliminares da Base, como já sinalizado, pois a vertente neoliberal está presente ao justificar a inclusão do inglês com vistas à integração no mundo, entendido como globalizado. Segundo afirma o PCN (2000): "Entender-se a comunicação como uma ferramenta imprescindível no mundo moderno, com vistas à formação profissional, acadêmica e pessoal, deve ser a grande meta do ensino de Línguas Estrangeiras Modernas no Ensino Médio" (BRASIL, 2000, p. 31). Demonstra-se nessa e em outras partes do texto uma preocupação em contemplar o ensino profissionalizante, que sirva ao mercado de trabalho de forma acrítica. Para a Base, segundo Malerba (2017), o caráter liberal se concretiza pelas próprias competências gerais que devem orientar o processo de construção do conhecimento em todas as áreas da educação básica.

Devemos destacar, também, como brevemente mencionado, que, na seção de Competências Gerais da Educação Básica, logo nas primeiras páginas da Base, por exemplo, já é feita uma relação entre ensino, diversidade e mercado de trabalho. Segundo o documento,

\footnotetext{
Valorizar a diversidade de saberes e vivências culturais e apropriar-se de conhecimentos e experiências que lhe possibilitem entender as relações próprias do mundo do trabalho e fazer escolhas alinhadas ao exercício da cidadania e ao seu projeto de vida, com liberdade, autonomia, consciência crítica e responsabilidade (BRASIL, 2018, p. 9, grifos nossos).
}

Para Szundy (2019), os grupos verbais como "fazer escolhas alinhadas" e os grupos nominais ou substantivos "projeto de vida", "liberdade" e "autonomia" estão "relacionadas à ideologia neoliberal" (2019, p. 126). Para a autora, embora existam ordens de indexicalidade coerentes com um paradigma sócio-histórico para a linguagem, a presença de marcadores neoliberais na redação da Base cria ideologias híbridas.Há, assim, uma "mascaração" de metas capitalistas por meio de um discurso de progressismo político (SZUNDY, 2019), o que torna, às vezes, a leitura neoliberal da BNCC menos óbvia. 
Percebemos, assim, mesmo que não tão explicitamente, indícios de que o ensino, a diversidade e o conhecimento parecem apenas interessar à educação brasileira, nessa narrativa construída pela Base, quando o estudante for capaz de relacioná-las, de alguma forma, ao mundo do trabalho. O estudante deve ser capaz de "entender" o mundo do trabalho para que consiga dele participar, visando, assim, a manutenção das relações sociais e trabalhistas. Essa natureza neoliberal da Base, também voltada para uma formação individual e profissionalizante em detrimento, por exemplo, de uma formação que privilegie a coletividade, já tem sido consistentemente denunciada em mais detalhes por diversos autores (e.g. CONSIDERA, 2019; GERHARDT; AMORIM, 2019; SZUNDY, 2019).

O conceito de competência que é apresentado nos documentos carrega em si essa vertente mercadológica, liberal. Na BNCC, percebe-se competência como algo a ser desenvolvido por etapas, cumulativo, como requisito para alcançar a nova etapa. Essa organização em competências também apresenta outra situação relevante, que é o fato de a BNCC ter aderido às ações da Agenda 2030 para o desenvolvimento sustentável da ONU e às avaliações externas, como o PISA (Programme for International Student Assessment), por exemplo, que traçam quadros comparativos entre os países participantes, gerando rankings, que estão associados ao recebimento de verbas internacionais. O ensino através de competências é uma orientação externa que está sendo inserida na educação brasileira aparentemente para servir aos propósitos de relações comerciais com outros países, transformados em metas.

Assim, as competências não estão fundamentadas em avaliações internas que representem as reais necessidades educacionais dos brasileiros em seus mais variados contextos geográficos e socioeconômicos. A preocupação estaria em mostrar um avanço nos índices, como assegura Cássio (2019). Para o autor,

para a melhoria dos indicadores educacionais, o governo federal e os reformadores empresariais da educação insistem em inverter a lógica, priorizando a produção dos indicadores para depois pensar na efetividade social das políticas educacionais. Sua principal estratégia para o agora: implementar um currículo nacional e obrigatório, baseado nos modelos de common core de outros países e fortemente vinculado às avaliações em larga escala - a BNCC. (CÁSSIO, 2019, p. 19, grifos do autor). 
À luz do exposto até o momento, percebemos que o componente língua inglesa continua a integrar o Ensino Básico brasileiro no Ensino Fundamental - Anos Finais - e no Ensino Médio, ao menos no primeiro ano. A língua inglesa é justificada por sua adoção global, por sua multiplicidade de usos na cultura digital e por "ampliar" as perspectivas pessoais e profissionais dos estudantes. Percebemos, também, que, ao impor apenas a inclusão da língua inglesa, a BNCC acaba apresentando ideologias híbridas, com ideais mercadológicos subjacentes à sua redação progressista. Nessa esteira, a Base acaba restringindo outras possibilidades de arranjos curriculares que abarquem outras línguas talvez mais interessantes para muitos dos contextos brasileiros, como já mencionado. Essa exclusão ancora-se no movimento de substituição da seção de língua estrangeira, da segunda versão da Base, por língua inglesa como língua franca, foco de nossas próximas seções.

\section{DA LÍNGUA ESTRANGEIRA À LÍNGUA FRANCA}

O ensino de inglês como língua estrangeira (ILE) foi instituído no Brasil nos tempos do império, não tratando-se, assim, de um conceito novo, já sendo carregado de vícios e preconceitos gerados por uma prática pedagógica que conta com pouca ou nenhuma condição de trabalho. $O$ conceito de LE, basicamente, faz referência a uma língua não nativa aprendida por meio da educação formal em unidades de ensino (LAGARES, 2018). É o que acontece no Brasil, por exemplo, com o ensino de inglês, que não é desenvolvido no âmbito familiar ou social, sendo introduzido pela escola por meio da instrução formal. Essa acepção de LE, então, carrega em si a ideia de uma língua externa ao estudante, de uma "língua do outro", de "outro território", perpetuando a ideia de falantes nativos idealizados. Dessa forma, o ensino de língua inglesa, muitas vezes, acaba sendo baseado em perspectivas hegemônicas e imperialismos linguísticos, a exemplo de práticas educativas pautadas exclusivamente pelo inglês estadunidense ou o britânico, tomando o falante nativo de uma dessas variedades como padrão único a ser seguido. Conforme afirma Gimenez (2015),

O inglês ensinado como língua estrangeira trabalha com noções de grupos situados geograficamente (geralmente Estados Unidos e 
Inglaterra), ignorando a complexidade de situações sociolinguísticas geradas a partir de interações multilíngues. Objetivos de aprendizagem são geralmente voltados para fazer com que os aprendizes se aproximem o máximo possível do falante nativo (GIMENEZ, 2015, p. 81).

Contudo, as novas diretrizes trazidas à tona pela BNCC passaram a tratar a língua inglesa como uma língua franca. Para analisarmos esse gesto de mudança, destacaremos, nesta seção, o que consideram as duas últimas versões da BNCC: a segunda versão (2016) e a terceira versão completa (2018), que inclui, também, a etapa do Ensino Médio.

A segunda versão da BNCC, de 2016, inicia o seu texto sobre as Línguas Estrangeiras Modernas mencionando as leis que regulam a sua oferta:

A Lei de Diretrizes e Bases da Educação Nacional (LDBEN, 9394/96) determina a inclusão de Língua Estrangeira Moderna entre os componentes obrigatórios da parte diversificada curricular, a partir do 60 ano do ensino fundamental (Art. 26, § 5o) até o 3o ano do Ensino Médio (Art. 36, inciso III). Propõe também que uma segunda língua estrangeira seja oferecida, em caráter optativo, e estipula que a escolha das línguas e de responsabilidade da comunidade escolar, de acordo com as possibilidades de cada instituição. No caso específico do Ensino Médio, a Lei 11.161/2005 determina que a língua espanhola seja obrigatoriamente ofertada nas escolas e facultada como matrícula ao estudante (BRASIL, 2016, p. 119).

Desse modo, amparada pela LDB (1996), a segunda versão da Base, divulgada após consulta popular, prevê a oferta obrigatória de línguas em todos os anos finais do Ensino Fundamental e Médio. Para o Ensino Médio, embora figure como um componente de matrícula facultativa para os alunos, o espanhol deve obrigatoriamente ser ofertado pela unidade escolar. Essa versão, de 2016, discorre, também, sobre o ensino de línguas estrangeiras não estar restrito apenas ao inglês e ao espanhol, abrindo, assim, possibilidades para a inclusão de outras línguas com base no plurilinguismo presente no país e nas possibilidades de comunicação através das redes sociais. Devemos observar que, nessa versão, o componente língua inglesa é descrito como uma LE, considerando a relação entre as línguas e as práticas sociais. A versão de 2016 concebe:

No componente Língua Estrangeira Moderna, enfatiza-se a compreensão de que as línguas nos constituem como sujeitos e que expressam valores que são construídos nas práticas sociais. Na etapa do Ensino Médio, 
amplia-se a vivência com a(s) língua(s) em estudo nas práticas sociais e aprofunda-se a reflexão sobre as relações entre língua, cultura, política e sociedade. (BRASIL, 2016, p. 514).

Para isso, a segunda versão da BNCC considera como fundamentos a educação linguística, os letramentos e a interculturalidade, trazendo à tona o desenvolvimento das competências através das práticas de linguagem, supondo a

\begin{abstract}
Superação de uma visão tecnicista de língua, limitada a explicações gramaticais ou a repetição de frases descontextualizadas, para priorizar uma perspectiva discursiva, que coloca a ênfase na produção de sentidos por parte dos/as estudantes, independentemente de seu nível de conhecimento da língua em dado momento. (BRASIL, 2016, p. 123).
\end{abstract}

Para um ensino que privilegie as práticas discursivas, a versão de 2016 direciona as práticas sociais para o trabalho interdisciplinar e a abordagem de temas que irão organizar os objetivos de aprendizagem, sendo elas: práticas da vida cotidiana, práticas artístico-literárias, práticas político-cidadãs, práticas investigativas, práticas mediadas pelas tecnologias digitais, e práticas do mundo do trabalho.

Na terceira versão da Base (2018), por outro lado, a visão plural de língua adquire outra forma. O documento inicia o trecho sobre a língua inglesa, atribuindo ao seu aprendizado um caráter formativo e a finalidade de um ensino consciente e crítico no Ensino Fundamental. Em seguida, introduz o questionamento:

Ensinar inglês com essa finalidade tem, para o currículo, três implicações importantes. A primeira é que esse caráter formativo obriga a rever as relações entre língua, território e cultura, na medida em que os falantes de inglês já não se encontram apenas nos países em que essa é a língua oficial. Esse fato provoca uma série de indagações, dentre elas, "Que inglês é esse que ensinamos na escola?" (BRASIL, 2018, p. 241).

Nesse trecho, assim como em outros momentos, podemos sentir que a própria Base critica o conceito de LE, atribuindo a esse um viés hegemônico. Desse modo, a nomenclatura língua estrangeira é substituída. A Base, em sua terceira versão, trata a língua inglesa, então, em seu status de língua franca devido o seu foco social e político.

Ao contrário do construto de LE, o conceito de inglês Língua Franca (ILF), presente na terceira versão da Base, é relativamente recente. Uma definição ampla de 
Língua Franca é a de uma língua que serviria de contato entre falantes de diferentes línguas maternas oriundos de contextos diversificados. Nessa concepção, ILF serviria como uma língua fronteiriça, por exemplo. Dessa forma, embasada no construto de língua franca, a seção destinada ao Ensino Fundamental na BNCC traz a ideia da língua desterritorializada como língua franca, justificado por sua abrangência global. $O$ componente língua inglesa, nessa versão final, parece ampliar os fundamentos apresentados na segunda versão, a saber: a educação linguística, os letramentos e a interculturalidade, ao apresentar a sua organização sob um caráter formativo, considerando três implicações: língua franca, os multiletramentos e a atitude do professor em acolher e legitimar diversas formas de expressão na língua. As implicações orientam para os seguintes eixos organizadores: Oralidade, Leitura, Escrita, Conhecimentos linguísticos e Dimensão cultural. A seção do Ensino Fundamental, na terceira versão, descreve as competências específicas da língua inglesa para a etapa, em consonância com as competências da área de Linguagens e prescreve Unidades Temáticas, objetos de conhecimento e habilidades a serem desenvolvidas.

$\mathrm{O}$ conceito de ILF se estende à seção do Ensino Médio, que cita a LDB para justificar a escolha da língua inglesa, como em:

Por sua vez, a Língua Inglesa, cujo estudo é obrigatório no Ensino Médio (LDB, Art. 35-A $\S 4^{\circ}$ ), deve ser compreendida como língua de caráter global - pela multiplicidade e variedade de usos, usuários e funções na contemporaneidade, assumindo seu viés de língua franca, como definido na BNCC do Ensino Fundamental - Anos Finais. (BRASIL, 2018, p. 476, grifo do original).

No trecho acima, a Base advoga a continuidade da língua inglesa como componente curricular, pois a orientação desta etapa seria uma continuidade ampliada da anterior. Em adição, a seção do Ensino Médio na terceira versão da Base tem a sua organização vinculada às competências da área de Linguagens, não havendo uma estruturação ou regulamentação específica para o inglês como componente curricular. A seção orienta para uma abordagem que integre as linguagens e suas práticas através de cinco campos de atuação social: da vida pessoal, das práticas de estudo e pesquisa, jornalístico-midiático, da atuação na vida pública e o campo artístico. 


\section{O PARADOXO DAS EXCLUSÕES}

Como já destacado, a alteração do status da língua inglesa de LE para língua franca, também culmina em sua imposição na última versão da Base. Uma das leituras possíveis é que o termo língua franca tenha sido usado para justificar a inserção exclusiva da língua inglesa na base curricular devido ao seu uso significativo nas relações comerciais, nas redes virtuais e em várias situações de prática social. Contudo, isso não confere, ou não deveria conferir, ao inglês exclusividade como língua franca, uma vez que várias outras línguas são utilizadas como línguas de contato, em diversos lugares, inclusive no Brasil.

Esses gestos em direção ao ensino de uma única língua obrigatória no currículo nacional contrariam a realidade de muitos alunos brasileiros que vivenciam zonas de contato e de conflito entre línguas (RODRIGUES, 2018). Para Júnior e Fernandes (2019), ao determinar o inglês como língua única, a BNCC "defende ações e um currículo preocupado com os interesses do mercado e do capital estrangeiro" (2019, p. 185), em detrimento daquilo que a comunidade escolar pode realmente necessitar. Em consonância com esse contexto, como já mencionado, podemos observar a presença dos representantes de mercados nos componentes do Movimento pela Base (formado pela Fundação Lemann, tendo como parceiros o Google, Instituto Natura, Instituto Unibanco e Itaú BBA ${ }^{9}$, por exemplo), um dos maiores apoiadores da criação e implementação da BNCC, reforçando um foco na manutenção do que é aparentemente de uso prático para o mercado brasileiro e interessante para as empresas privadas apoiadoras da BNCC. Além disso, perpetua-se a ideia de que o aprendiz contemporâneo somente pode "acessar o chamado mundo globalizado e plural pelo prisma da língua inglesa" (JÚNIOR; FERNÁNDEZ, 2019, p.193).

O status de língua franca por si só não deveria justificar a exclusividade da língua inglesa no currículo da Educação Básica, em concordância com a afirmação de Vilaço e Grande (2019):

\footnotetext{
${ }^{9}$ Conforme o "Movimento pela Base". Disponível em: $<$ http://movimentopelabase.org.br $>$. Acesso em: 28 abr. 2020 .
} 
Ao indicar o status da Língua Inglesa como língua franca - o qual desvincularia "da noção de pertencimento a um determinado território" a BNCC apenas apresenta uma abordagem para o ensino de língua e não justifica a escolha do inglês, ao contrário do que a sua argumentação parece indicar. (VILAÇO; GRANDE, 2019, p. 148).

Embora esse termo supostamente esteja desvinculado dos imperialismos, normalmente atribuídos ao termo língua estrangeira ou à adoção do padrão nativo como alvo de ensino, escolher a língua inglesa como possibilidade única pode revelar justamente uma leitura imperialista, impositiva do inglês frente às outras línguas dado o seu perfil global e ao seu valor de mercado. Isso fortalece, também, a relação feita entre a BNCC e as organizações externas, através da valorização de avaliações como o PISA, que sugerem o trabalho pedagógico com base no desenvolvimento de competências, e participação em organizações como a ONU, na qual o inglês é uma língua de trabalho.

Muito embora o texto que trata da língua inglesa, em isolamento, talvez não se traduza em um movimento repressor, o fato de sua promulgação suprimir outras possibilidades de inclusões de línguas não nativas, constrói um cenário, no contexto geral da BNCC, de repressão linguística, porque institui o ensino exclusivo da língua inglesa como componente curricular na Educação Básica. Trata-se de uma contradição, a ideia de uma língua franca, considerada como língua de contato entre falantes nativos de outras línguas, não deveria ser sustentada por movimentos de hegemonia linguística, modelados por meio da exclusão curricular, documental, de outras línguas. Para Calvet (2007), estados intervêm no domínio linguístico com frequência através de políticas linguísticas repressoras, sobretudo em movimentos de homogeneização. Nesse sentido, a seção de língua inglesa não deve ser contemplada em isolamento.

Assim, a Base exclui a possibilidade do estudo de outras línguas não nativas como componentes curriculares, ideia que era defendida na segunda versão do documento, oriunda da consulta popular. A nova determinação da língua inglesa como componente imposto para todo os ciclos, configura-se, de certa forma, como um problema para a construção de currículos em diversos contextos, pois "a impossibilidade de se fazer outra opção é autoritária, fechando uma das portas que mais favoreciam a pluralidade cultural e a diversidade dos currículos e da formação oferecida nas escolas brasileiras" (VILAÇO; GRANDE, 2019, p. 150). Nesse sentido, muito embora tomar a língua inglesa como uma 
língua franca seja, ao menos em nossa opinião, um grande avanço, ao versar sobre exclusão de outras possibilidades, a Base vai na direção contrária ao próprio discurso e ao construto de língua franca, das relações sociais. Esse "silenciamento de outras possibilidades" pode ser lido como um movimento de uma política linguística direcionada a uma instrumentalização das línguas para o mercado de trabalho, lógica contrária à fluidez do ILF. Cria-se um paradoxo.

Também devemos problematizar a mudança de ILE para ILF face às reais condições de formação continuada dos professores brasileiros. Aparentemente, as consultas populares com professores, conduzidas para as primeiras versões da Base, foram silenciadas na última versão do documento. Contudo, os professores não podem continuar excluídos após a implementação do documento. Para Rocha e de Melo (2019), a BNCC é um documento "oficial burocrático que se apresenta e se mantém numa esfera dificilmente alcançável pela maioria das(os) professoras(es) do país" (ROCHA; DE MELO, 2019, p.219). Em outras palavras, a BNCC é um documento que pode não ser aplicado na prática se não houver um movimento de formação (inicial e continuada) adequada aos profissionais de ensino, impossibilitando a transição da LE para a LF e permitindo, assim, a perpetuação de uma forma tradicional de ensino enraizada no inglês como língua estrangeira, língua do outro. Tendo em vista que o trabalho aplicado no ensino de língua estrangeira nas escolas de Ensino Básico foi, em sua grande parte, estrutural e metalinguístico, com grande ênfase em gramática, a formação docente continuada será necessária. "Certamente será difícil que [professores] consigam ler com profundidade as 527 páginas do documento a fim de se aperfeiçoar e seguir as orientações nacionais" (ROCHA; DE MELO, 2019, p. 219).

Em adição, como formadores de professores e professores de esferas públicas de ensino, entendemos que o termo ILF ainda causa estranhamento. Percebemos que a publicação do documento não garante que um conceito proposto, como é o caso do ILF, não seja entendido como apenas mais uma nova idealização que não sairá do nível conceitual tampouco garante que o termo ILF não seja, por exemplo, aplicado, na prática, como um mero sinônimo de ILE. Quando o professor recebe um documento dessa importância, aparentemente bem direcionado, normalmente não é induzido a questionar e ocupar seu pouco tempo extraclasse para pesquisar e/ou aprofundar-se nos conceitos 
propostos. Isso acontece porque a falta de incentivo à formação continuada dos professores brasileiros é secular. Muitos ficarão apenas na leitura superficial da Base que pode, consequentemente, direcionar a práticas pedagógicas distintas.

\section{O PARADOXO DO NOVO TRADICIONAL}

Outro questionamento a ser feito é sobre a continuidade da forma de ensino da língua inglesa. A homologação e implementação da BNCC não garantem que o ensino do inglês possa realmente adaptar-se à proposta de língua franca, trabalhada em sua dimensão intercultural e que contemple os multiletramentos. Mesmo sendo tratada como língua franca, a arquitetura de ensino da língua inglesa é a mesma, compreendendo uma ou duas aulas semanais com o mesmo tipo de material didático e condições de ensino. Ou seja, por enquanto, a mudança ocorre apenas no documento, a estrutura do ensino continua com o mesmo desenho de uma ou duas aulas semanais. Esse modelo em que uma língua hegemônica é introduzida em algumas aulas semanais no ensino regular é considerado por Lagares (2018) a origem do insucesso do ensino de línguas em aulas regulares no Brasil. Dessa forma, a mudança que vemos no texto da Base pode configurar como apenas uma mudança na designação para a língua inglesa, sem que sejam vistas mudanças efetivas nas práticas pedagógicas, já que o sistema, a carga/horária, as condições estruturais escolares, bem como outros fatores são os mesmos.

Para Rajagopalan (2019), os termos currículo e ensino são considerados como se designassem uma ordem cronológica, revelando mais um paradoxo entre ILF no nível teórico da Base e sua proposta de prática, de conteúdos essenciais. Nesse sentido, podemos observar traços de ensino tradicional na Base, por exemplo, na sequência de conteúdos programáticos por série na seção de língua inglesa. Na sequência prescrita para o ensino do ILF, no sexto ano aprende-se o "tempo presente", no sétimo ano, "o passado", com ênfase ao aprendizado sobre a pronúncia do "-ed" em verbos regulares, e, "obviamente", no oitavo, os estudantes desenvolvem o "tempo futuro". De certa forma, então, fica evidente que a sequência de aprendizagem mínima proposta pela BNCC para o componente curricular língua inglesa perpetua a ideia de que um único currículo homogeneizaria a aprendizagem, que se daria de maneira linear. Muito embora a fundamentação teórica da Base traga à tona a língua franca, que tem como foco a 
inteligibilidade e não acurácia da produção linguística, o currículo proposto, as "aprendizagens essenciais", mantêm uma organização de conteúdos muito semelhante à anteriormente trabalhada no ensino como língua estrangeira. A proposta, em termos práticos, é tradicional.

Esses gestos são evidência de que Berticelli (1997) foi coerente ao afirmar, em relação à educação brasileira, que "não há dúvidas de que os humanos se acostumaram ao pensamento ordenado proposto por Descartes" (BERTICELLI, 1997, p. 135). Percebemos, mesmo nos documentos mais recentes que regulam o ensino de línguas no território nacional, a perpetuação da ideia de que um currículo bem elaborado e linear, ordenado, assim como aponta Rajagopalan (2019), garantiria uma aprendizagem bem-sucedida. Além disso, não podemos deixar de mencionar que, diante de um documento e de um ordenamento de aprendizagens tão extensos, no contexto educacional brasileiro, não acreditamos que haja tempo para que nossos docentes consigam ir além do "mínimo", limitando (ou impedindo), por exemplo, as discussões sobre as realidades locais.

$\mathrm{Na}$ crista dessa discussão, a Base define, em meio ao seu ordenamento curricular, o que deve ser aprendido pelos estudantes brasileiros, como anteriormente sinalizamos. Vejamos dois importantes fragmentos do Base, com destaque nossos:

Trata-se, portanto, de maneiras diferentes e intercambiáveis para designar algo comum, ou seja, aquilo que os estudantes devem aprender na Educação Básica, o que inclui tanto os saberes quanto a capacidade de mobilizá-los e aplicá-los (BRASIL, 2018, p. 12, grifos nossos).

Por meio da indicação clara do que os alunos devem "saber" (considerando a constituição de conhecimentos, habilidades, atitudes e valores) e, sobretudo, do que devem "saber fazer" (considerando a mobilização desses conhecimentos, habilidades, atitudes e valores para resolver demandas complexas da vida cotidiana, do pleno exercício da cidadania e do mundo do trabalho), a explicitação das competências oferece referências para o fortalecimento de ações que assegurem as aprendizagens essenciais definidas na BNCC (BRASIL, 2018, p. 13, grifos nossos).

Esses dois fragmentos revelam que o documento busca instituir um conjunto de "aprendizagens essenciais". Mas o que muitos têm questionado é: essenciais para quem? Igualdade educacional tendo que falante e que cidadão em mente? Nesse ponto, 
Rajagopalan (2019, p. 29) aponta que "quando se propõe um mesmo remédio para um universo tão diverso, estamos de fato, imaginando um sujeito ideal como receptor do tratamento". Estamos mantendo a ideia de que o desenvolvimento de línguas segue ordenamento serial, que deveria estar vencido. São resquícios de uma política educacional que tem a ciência moderna como único suporte teórico, amparada, também, em uma perspectiva utilitária para a língua inglesa. Seriam aprendizes/cidadãos autômatos ideias que devem ser guiados pelas mesmas regras? Seriam as "aprendizagens essenciais" essenciais para todos? Cria-se um paradoxo entre a teoria de língua franca na redação da Base e o que é proposto no nível de competências e aprendizagens essenciais, homogeneizantes.

Pensamos que o ILF é evidência do oposto. É evidência que a língua é uma Sistema Adaptativo Complexo (e.g. BECKNER et al., 2009). ILF é índice de que o universo é altamente heterogêneo, conforme a própria segunda versão da Base, ancorada na consulta popular, sinalizava, em relação ao Brasil, com "acentuada diversidade cultural e profundas desigualdades sociais" (BRASIL, 2016). Quando discutimos, então, a língua inglesa dentro da última versão da Base, ficamos nos perguntando "que estudante é esse?". Ainda podemos perceber de um construto imaginário de "alunos ideais", com demandas educacionais iguais em todos os contextos brasileiros, que originam um conjunto mínimo estático de aprendizagens. Estaríamos falando, então, em um cidadão brasileiro ideal? Vemos, em parte da Base, na estruturação curricular proposta, uma ideologia que ainda preconiza a língua inglesa como resultado, como produto de um processo linear baseado no ganho. Há um descompasso entre teoria e proposta de prática.

Entramos aqui em mais uma discussão efervescente na área. Sifakis et al. (2018) salienta que não devemos esperar que os pressupostos do ILF sejam facilmente traduzidos em práticas educativas, em uma Base, por exemplo. Para esses autores, isso revela uma questão sobre como a conexão entre o ILF e o ILE poderia ser alcançada: os profissionais da área da linguagem deveriam totalmente substituir as práticas de ILE por ILF ou deveriam combinar ILE e ILF? Para aqueles que, segundo Sifakis et al. (2018), defendem à troca total de práticas, a BNCC está manifestamente equivocada, pois o nível estrutural do documento (o currículo, as "aprendizagens essenciais") não corresponde ao nível teórico, à redação da seção sobre a língua inglesa. Por outro lado, aqueles que defendem a 
integração entre ILE e ILF, ainda para Sifakis et al. (2018), por exemplo, deveriam primeiramente investigar os desejos e necessidades de seus estudantes. Os professores devem, assim, ser autônomos o suficiente para fazer as adaptações necessárias para essa integração entre ILE e ILF (SIFAKIS et al., 2018). Contudo, percebemos que fazer isso face à BNCC é uma missão hercúlea, pois o documento propõe uma flexibilização horizontal, na qual conhecimentos diversos podem ser agregados ao patamar mínimo, e não uma flexibilização vertical, em relação à organização dos conhecimentos demandados ancorados na realidade dos estudantes e escolas brasileiras (CONSIDERA, 2019). Os profissionais de línguas brasileiros, realmente engajados com a educação básica nacional, poderiam, além de cobrir os conteúdos mínimos (em nossa opinião completamente utópicos), adicionar facilmente tópicos que busquem a integração com o ILF? Fica, então, o desafio. Percebemos que embora o prisma teórico da base efetivamente crie uma narrativa academicamente coerente em relação à adoção do construto da língua franca em detrimento de língua estrangeira, essa própria narrativa acaba pondo em xeque outras partes do documento.

\section{CONSIDERAÇÕES FINAIS}

Sem negarmos a importância da língua inglesa no currículo brasileiro e sempre levando em consideração os avanços teóricos da Base, neste trabalho, buscamos apresentar uma leitura analítica, reflexiva e ativa desse documento. Nesse sentido, buscamos abordar as mudanças nos direcionamentos do componente curricular língua inglesa entre as duas últimas versões da Base. Dessa forma, discutimos a transição do caráter estrangeiro para o caráter franco da língua inglesa na redação da BNCC, refletindo sobre as suas implicações conceituais e práticas, bem como sobre exclusão de outras línguas não nativas. Destacamos, também, alguns paradoxos criados entre aporte teórico e currículo, enquanto estrutura, na Base em relação ao ensino de língua inglesa, corroborando Siqueira, Lopriore e Grazzi (2020), que sinalizam que o falar nativo ainda está profundamente entrincheirado na educação escolar. Há um foco no desenvolvimento de competências, muitas vezes estruturais (e.g., gramática e pronúncia), dando foco à acurácia e a linearidade em detrimento à inteligibilidade e à variação, construtos inerentes à própria língua franca. A BNCC destaca quais competências os estudantes devem 
desenvolver ao final dos ciclos, mas não o aprendizado de capacidades de questionamento, por exemplo, dos próprios motivos que levam a essas competências e aprendizagens essenciais a serem tomadas como default, como pertencentes ao futuro cidadão brasileiro "comum".

\section{REFERÊNCIAS}

AGUiAR, M.; TUTTMAN, M. Políticas educacionais no Brasil e a Base Nacional Comum Curricular: disputas de projetos. Em Aberto, Brasília, v.33., n.107, p.69-94, jan./abr., 2020.

BECKNER, C.; BLYTHE, R.; BYBEE, J.; CHRISTIANSEN, M.; CROFT, W.; ELLIS, N.; HOLLAND, J.; KE, J.; LARSEN-FREEMAN, D.; SCHOENEMANN, T. Language is a complex adaptive system: position paper. Language Learning, v.59, n.1, p.1-26, dec., 2009.

BERTICELLI, I. A. Educação: auto-organização e complexidade. Cadernos de Educação, UFPEL, v.9, n.1, p.115-127, 1997. Disponível em: $<$ https://periodicos.ufpel.edu.br/ojs2/index.php/caduc/article/download/6586/4557>.

Acesso em: 10 ago. 2020.

BRASIL. Ministério da Educação. Base Nacional Comum Curricular. Brasília: MEC/SEB, Conselho Nacional de Secretários de Educação - CONSED. União Nacional dos Dirigentes Municipais de Educação - UNDIME. 11 de maio de 2018. Disponível em: $<\underline{\text { http://basenacionalcomum.mec.gov.br/images/BNCC_EI_EF_110518_versaofinal_site.p }}$ df >. Acesso em: 26 out. 2020.

. Ministério da Educação. Base Nacional Comum Curricular. Educação é a Base. Brasília: MEC/SEB, Conselho Nacional de Secretários de Educação - CONSED. União Nacional dos Dirigentes Municipais de Educação - UNDIME. 2017.

. Ministério da Educação. Base Nacional Comum Curricular. Brasília: MEC/SEB, Conselho Nacional de Secretários de Educação - CONSED. União Nacional dos Dirigentes Municipais de Educação - UNDIME. 2a versão, abril de 2016. Disponível em: $<$ https://undime-sc.org.br/download/2a-versao-base-nacional-comum-curricular/>. Acesso em: 30 out. 2020 .

Ministério da Educação. Base Nacional Comum Curricular. Consulta Pública. Brasília: MEC/SEB, Conselho Nacional de Secretários de Educação - CONSED. União Nacional dos Dirigentes Municipais de Educação - UNDIME, 2015. Disponível em: $<$ https://undime.org.br/noticia/11-03-2016-12-42-relatorios-das-contribuicoes-estaodisponiveis-no-portal->. Acesso em: 30 out. 2020. 
Lei $n^{o}$ 13.415, de 16 de fevereiro de 2017b. Disponível em: $<$ http://www.planalto.gov.br/ccivil_03/_Ato2015-2018/2017/Lei/L13415.htm>. Acesso em: 29 abr. 2020.

Lei de Diretrizes e Bases da Educação Nacional. Lei $\mathrm{n}^{\circ}$ 9.394, de 20 de dezembro de 1996, que estabelece as diretrizes e bases da educação nacional. - 13. ed. Brasília: Câmara dos Deputados, Edições Câmara, 1996. Disponível em: <http://www.planalto.gov.br/ccivil_03/leis/19394.htm>. Acesso em: 10 abr. 2020.

Ministério da Educação. Orientações Curriculares para o Ensino Médio Linguagens, códigos e suas tecnologias. Brasília: MEC/SEB, 2006. Disponível em: $<$ http://portal.mec.gov.br/seb/arquivos/pdf/book_volume_01_internet.pdf $>$. Acesso em: 26 out. 2020.

. Ministério da Educação. Parâmetros Curriculares Nacionais - Ensino Médio. Parte II: linguagens, códigos e suas tecnologias. Brasília, 2000. Disponível em: $<$ http://portal.mec.gov.br/seb/arquivos/pdf/14_24.pdf>. Acesso em: 10 abr. 2020.

. Ministério da Educação. Parâmetros Curriculares Nacionais - terceiro e quarto ciclos do Ensino Fundamental. Brasília: MEC/SEF, 1998. Disponível em: <http://portal.mec.gov.br/seb/arquivos/pdf/introducao.pdf>. Acesso em: 10 abr. 2020.

Ministério da Educação. Parâmetros Curriculares Nacionais: introdução aos parâmetros curriculares nacionais. Brasília: MEC/SEF, 1997. Disponível em: <http://portal.mec.gov.br/seb/arquivos/pdf/livro01.pdf>. Acesso em: 26 out. 2020.

Resolução CNE/CEB $n^{\circ}$ 7. Diretrizes Curriculares Nacionais para o Ensino Fundamental de 9 (nove) anos. 14 de dezembro de 2010. Diário Oficial da União, DF, 15 dez. 2010. Disponível em: <http://portal.mec.gov.br/dmdocuments/rceb007_10.pdf>. Acesso em: 10 abr. 2020.

CALVET, L. As políticas linguísticas. Tradução: Isabel de Oliveira Duarte, Jonas Tenfen, Marcos Bagno. São Paulo: Parábola Editorial: IPOL, 2007 [1942].

CÁSSIO, F. Existe vida fora da BNCC? In: CÁSSIO, F.; CATELLI JR., R. (Orgs). Educação é a Base? 23 educadores discutem a BNCC. São Paulo: Ação Educativa, p.1339, 2019.

CONSIDERA, A. Um museu de grandes novidades: a reforma do Ensino Médio e a BNCC. In: GERHARDT, A.; AMORIM, M. (Orgs.). A BNCC e o ensino de línguas e literaturas. Campinas, SP: Pontes Editores, p. 41-86, 2019.

COSTA, C. Novos golpes, velhas práticas: direito à informação, memória e reparação. In: GALVÃO, A.; ZAIDAN, J.; WILBERTH, S. (Orgs.) Foi Golpe! O Brasil de 2016 em análise. Campinas, São Paulo: Pontes Editores, 2 ed., p.117-133, 2019. 
CURY, C.; REIS, M.; ZANARDI, A. Base Nacional Comum Curricular: dilemas e perspectivas. São Paulo: Cortez, 2018.

GERHARDT, A.; AMORIM, M. Olhares indisciplinares sobre a BNCC.In: GERHARDT, A.; AMORIM, M. (Orgs). A BNCC e o ensino de línguas e literaturas. Campinas, SP: Pontes Editores, p. 17-22, 2019.

GIMENEZ, T. Renomeando o inglês e formando professores de uma língua global. Estudos Linguísticos e Literários, v.52, p.73-93, 2015. Disponível em: $<$ https://portalseer.ufba.br/index.php/estudos/article/view/15464> Acesso em: 14 fev. 2020.

GOMES, J.; GALVÃO, A. Educação escolar e democracia em tempos de "Escola sem partido". In: GALVÃO, A.; ZAIDAN, J.; WILBERTH, S. (Org.) Foi Golpe! O Brasil de 2016 em análise. Campinas, São Paulo: Pontes Editores, 2 ed., p.239-259, 2019.

LAGARES, X. Qual política Linguística?: Desafios glotopolíticos contemporâneos. 1. ed. São Paulo: Parábola, 2018.

LOPES, E.; CAPRIO, M. As influências do modelo neoliberal na educação. Revista online de Política e Gestão Educacional, v.5, p.1-16, 2018. Disponível em: $<$ https://periodicos.fclar.unesp.br/rpge/article/view/9152>. Acesso em: 26 out. 2020.

MALERBA, J. Uma análise da Base Nacional Comum Curricular. 2017. Disponível em: $<$ https://www.cafehistoria.com.br/uma-analise-da-base-nacional-comum-curricular $>$. Acesso em: 26 abr. 2020.

PLANK, D. Implementing the BNCC: Lessons from "Common Core". Lemman Center. Stanford Graduate School of Education. 2016. Disponível em: $<$ http://lemanncenter.stanford.edu/sites/default/files/Implementing\%20merged\%20English \%281\%29_0.pdf>. Acesso em: 26 abr. 2020.

RAJAGOPALAN, K. Reforma curricular e ensino. In: GERHARDT, A.; AMORIM, M. (Org.). A BNCC e o ensino de línguas e literaturas. Campinas, SP: Pontes Editores, p.2340, 2019.

ROCHA, L.; DE MELO, G. Onde ficam raça e gênero na BNCC do ensino médio? A homogeneização das diferenças. In: GERHARDT, A.; AMORIM, M. (Org.). A BNCC e o ensino de línguas e literaturas. Campinas, SP: Pontes Editores, p. 209-238, 2019.

RODRIGUES, F. Direito linguísticos, legislação e educação: formação em línguas no Brasil. In: SOUSA, S.; PILAR ROCA, M.; PONTE, A. (Org.). Temas de política linguística no processo de integração regional. Campinas, SP: Pontes Editores, p.67-78, 2018.

SIFAKIS, N. S; LOPRIORE, L.; DEWEY, M.; BAYYURT, Y.; VETTOREL, P.; CAVALHEIRO, L.; SIQUEIRA, S.; KORDIA, K. ELF-awareness in ELT: Bringing 
together theory and practice. Journal of English as a Lingua Franca, v.7, n.1, p.155-209, 2018. Disponível em: <https://doi.org/10.1515/jelf-2018-0008>. Acesso em: 10 ago. 2020.

SILVA JÚNIOR, A.; FERNÁNDEZ, G. Ausência da língua espanhola na Base Nacional Comum Curricular: quais implicações esperar? In: GERHARDT, A.; AMORIM, M. (Org.). A BNCC e o ensino de línguas e literaturas. Campinas, SP: Pontes Editores, p.181208, 2019.

SIQUEIRA, S.; LOPRIORE, L.; GRAZZI, E. ELF awareness and pedagogical implications in ELT classrooms. Introduction to special issue. Estudos Linguísticos $e$ Literários, v.65, p.1-4, 2020. Disponível em: $<$ https://portalseer.ufba.br/index.php/estudos/article/view/36465 >. Acesso em: 03 mar. 2020.

SZUNDY, P. A base nacional comum curricular e a lógica neoliberal: que línguas(gens) são (des)legitimadas? In: GERHARDT, A.; AMORIM, M. (Org.). A BNCC e o ensino de linguas e literaturas. Campinas, SP: Pontes Editores, p.121-152, 2019.

TÍLIO, R. A Base nacional comum curricular e o contexto brasileiro. In: GERHARDT, A.; AMORIM, M. (Org.). A BNCC e o ensino de línguas e literaturas. Campinas, SP: Pontes Editores, p.7-16, 2019.

VILAÇO, F; GRANDE, G. Língua Inglesa na BNCC. In: CÁSSIO, F.; CATELLI JR., R. (Org.). Educação é a Base? 23 educadores discutem a BNCC. São Paulo: Ação Educativa, p. 145-157, 2019.

Recebido em: 30 abr. 2020. Aceito em: 05 out.2020. 